\title{
ARTIFICIAL LIGHT AT NIGHT AS AN UNRECOGNIZED THREAT TO PROTECTED AREAS OF AUTONOMOUS PROVINCE OF VOJVODINA (NORTH SERBIA)
}

\author{
Dajana Bjelajac ${ }^{A}$, Bojan Đerčan ${ }^{A}$ \\ Received: April 19, 2019 | Accepted: June 24, 2019 \\ DOI: 10.5937/ZbDght1901046B
}

\begin{abstract}
In the last two decades, artificial light at night has increased at alarming rates on global level and numerous negative effects of excessive artificial lighting are characterized as light pollution. However, light pollution has not gained enough attention such as water or air pollution, even though researchers are finding more and more evidence of its adverse impact on the environment. This phenomenon is mostly unknown in Serbia (and wider region), and consequences of light pollution have not yet been assessed. Autonomous Province of Vojvodina has 165 protected areas which cover a surface of approximately 2048 $\mathrm{km}^{2}$ and are home to a large number of strictly protected species. Furthermore, due to its geographical location and characteristics of the relief, Vojvodina is intersected by numerous ecological corridors, especially for avifauna. Likewise, this region is also highly populated and has dense road network which is usually located nearby protected areas. Since artificial lighting is present wherever there are human activities, it can be assumed that protected areas and ecological corridors in Vojvodina Province are endangered with light pollution. The aim of this paper is to present the basic concept of light pollution problematic, and to define the biggest light emitters in Vojvodina and surrounding in order to outline the most endangered protected areas by this pollutant.
\end{abstract}

Keywords: light pollution, Serbia, ecology, ALAN, urbanization

\section{INTRODUCTION}

The only evidence of human activity on the planet, uniquely visible form the space, are lights at night. Most of the lights are emitted from settlements and ephemeral fires, but also from the gas flares, offshore platforms and heavily lit fishing boats (Aubrecht et al, 2010). Nevertheless, artificial light at night (ALAN) is considered as one of the great-

A University of Novi Sad, Faculty of Sciences, Department of Geography, Tourism and Hotel Management, Novi Sad, Serbia; contact: dajana.bjelajac92@gmail.com 
est threats to biodiversity worldwide. The most important consequence of alteration of natural day-night cycle caused by ALAN is desynchronization of biological rhythm and its environment which leads to disruption of the vital functions such as feeding and reproduction (Gaston et al., 2014; Azam et al, 2018). However, since artificial lighting has become one of the crucial factors of economic growth of our civilization it is necessary to define which type of lighting is degrading natural environment and vice versa, which type of lighting can be considered as ecologically approved. Therefore, light pollution can be defined as an alteration of light levels in the outdoor environment during the night hours, or such alteration of light levels in the indoor environment that harms human health due to man-made sources (Hollan, 2009). Autonomous Province of Vojvodina is located in the southern parts of Pannonian basin and it has been a transitional area from both, sociological and ecological point of view. Not only rivers and wide plains are used as natural passage for aquatic and land animals, but there are also important migratory paths for avifauna. Furthermore, Vojvodina has 165 protected areas which cover a surface of approximately $2048 \mathrm{~km}^{2}$ and are home to a large number of strictly protected species (Tomić et al., 2004). On the other hand, most of the protected areas are situated in the vicinity of larger settlements e.g. because of its fertile soils and suitable climate most of the outskirts of National Park Fruška gora are significantly populated. Besides the proximity of protected nature and urban areas, another major contributor to overall amount of light pollution in Vojvodina plain is the orography of the terrain. The highest peak of the investigated area is only 641 meters above the sea level, thus, most of the improperly installed artificial lighting can spread for kilometers away from the source. This type of light pollution can be characterized as a light cluster - excessive groupings of lights which amplify the sky glow effect.

So far, there are no data about the amount or the negative effects of light pollution in the investigated area, cause most of the research has been focused on the traditional types of pollution, such as air and water pollution. As mentioned above, Vojvodina has several factors that can greatly contribute to harmful effect of excessive amount of artificial lighting. Thus, it is necessary to provide basic information on causes of light pollution and its current state, but also to identify potentially endangered protected areas in order to set appropriate mitigation measures.

\section{CAUSES AND CONSEQUENCES OF LIGHT POLLUTION}

First of all, it is necessary to highlight the difference between natural and artificial lighting. Natural, or zodiacal lighting during the night hours are the sum of the Sun's rays that are reflected by the moon and other celestial bodies and light emitted from surrounding stars (Mizon, 2002). Artificial lighting is used to deliberately illuminate space with practical or aesthetic purpose. All negative products of this type of lighting are studied under the context of light pollution. In order to identify sources of light pollution, it is crucial to determine the nature of artificial light propagation in the atmosphere and spectral characteristics of the light bulbs. The largest part of the polluting light spreads due to the inadequate construction of public lighting and the reflections off 
the ground. The amount of unproductive light emitted by public luminaries depends on the amount of luminous flux which passes over the horizon. Improper constructions of luminaries are primarily reflected in the use of shielding on lighting fixtures, the height of the lamppost and the angle at which the lamp is positioned in relation to the horizon. Figure 1. represents three types of public luminaries (aligned with the horizon) based on their fixtures: non-cutoff, semi-cutoff, and full-cutoff luminaries. It is evident that example A emits the most of the luminous flux above the horizon while the full-cut off luminaries emit the light completely bellow horizon. Although example $\mathrm{C}$ is the most acceptable ecological solution for the public lighting, it is still contributing to light pollution through the reflection of the ground (usually between $5-10 \%$ of overall luminous flux) (Mohar, 2005, Mikuž and Zwitter, 2005).

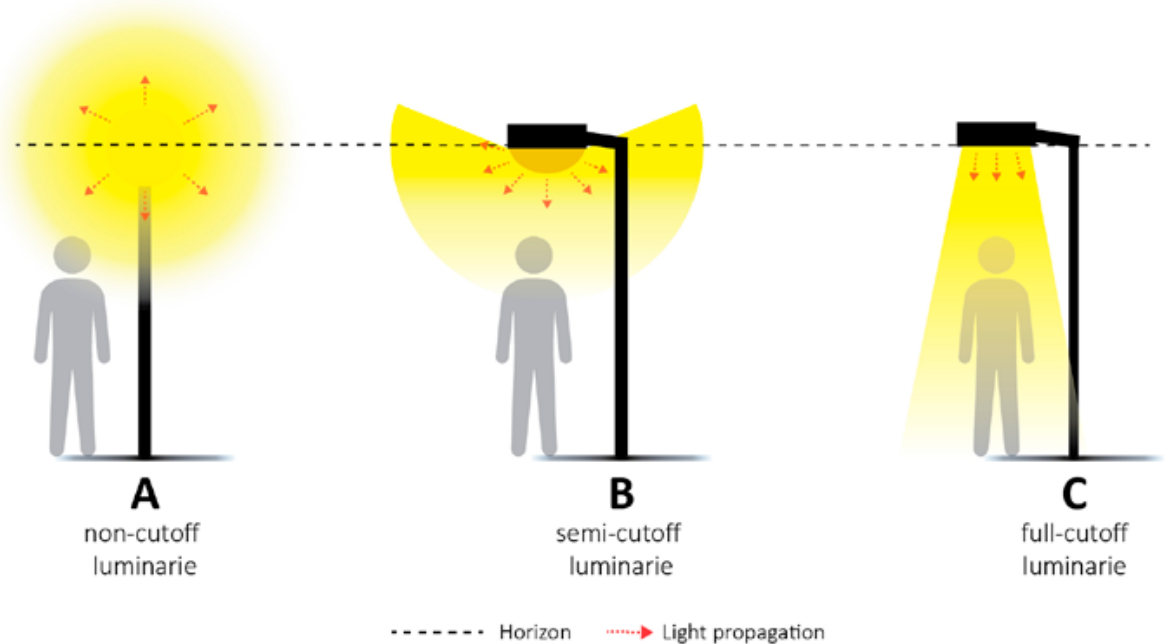

Figure 1. Different types of luminaries and light propagation (Source adapted from Mikuž and Zwitter, 2005)

Luminaries with low angle against the horizon have the longest rays that penetrate deep into the atmosphere (Figure 2). While the value of the angle is increasing, the pollution is decreasing because the light remains concentrated around the source, however, it contributes more to the intensity of the light pollution around the source. Luminaries with 0-5 degrees above the horizon are the biggest pollutants because their rays extend to approximately $200 \mathrm{~km}$ in length. So called, "sky glow", in unpopulated areas is caused mainly because of the merging this kind of distant light sources (Mikuž and Zwitter, 2005)

As it was mentioned before, the height of the lamppost is playing an important role in the propagation of luminous flux. If the height of the lamppost is dominant amongst buildings and vegetation, the light spreads continuously in the atmosphere without any obstacles [16]. Besides improper construction of public lighting equally important are the spectral characteristics of the luminaries. This is a very broad topic, and for the purposes of this study only the basic features of light spectrum will be explained. The tradi- 


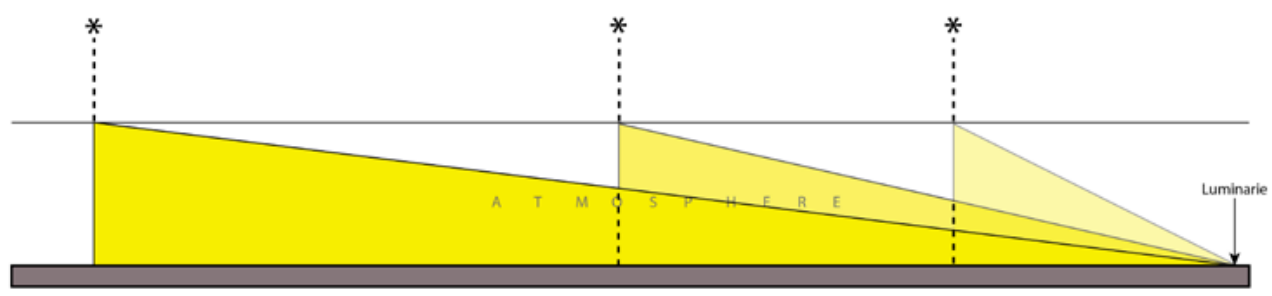

Figure 2. Propagation of luminous flux towards the angle of luminaire against the horizon (Source adapted from Mikuž and Zwitter, 2005)

tional type of lamps used for public and private lighting are with low-pressure sodium light bulbs. These luminaries emit only a narrow part of the spectrum in the orange-yellow light and are relatively unattractive to insects. They have maximum efficiency and a fairly long life up to 16,000 hours (Mohar, 2005; Falchi et al., 2011). However, Light Emitting Diodes (LED's) are rapidly taking over the lighting industry since they are the best energy efficient lighting invented so far $(95 \%$ more efficient than incandescent light bulbs). Nevertheless, lighting industry is promoting so called "white" LED lights which consist of a blue light-emitting diode and phosphor (fluorescent) coating. Blue light is high-energy, short-wave length light and although it is present in sunlight, blue light needs to be balanced by all other colors of light, particularly its opposite color of light red. Yet, red light is absent in traditional fluorescent and LED lights and this can be very harmful not only to nocturnal, but also to daytime species including humans (Report of the council on science and public health, 2016). The best ecological solution for public and private lighting which is at the same time energy efficient and doesn't harm living beings is LED light with the color temperature bellow $2700 \mathrm{~K}$. Most of the outdoor artificial lighting comes from street lighting which is usually very hard to reduce because of the safety issues. However, large portion of light pollutants are in a form of public areas lighting (such as parks, parking spots), house lighting, decorative lighting and commercial buildings lighting (Falchi et al., 20111; Kyba et al., 2015).

In general, all negative impacts of light pollution can be divided into the following groups:

- Environmental/Visual pollution (sky glow, glare, and light trespass)

- Human health degradation

- Negative impact on ecosystems (animals, plants)

- Economic and energy losses (Mizon, 2002; Lyytimäki, 2013; Elsharagty and Kim, 2015)

The most obvious consequence of over intensive and inappropriate public and private lighting is sky glow (figure 3). This form of light pollution is caused by light that is either emitted directly upward by luminaires or reflected from the ground and scattered by dust and gas molecules in the atmosphere, producing a luminous background. Accordingly, the first people that expressed concerns about this phenomenon are amateur and professional astronauts, which lost their view of the celestial bodies (Riegel, 1973; Crawford, 1991). Despite their repeated warnings the trend toward brighter nights continued with not only damaging the aesthetic value of starry night, but also the per- 
ception of moonlight nights by mankind (Cinzano et al., 2001; Lyytimäki et al., 2012; Lyytimäki, 2015). Almost 20 years ago, McNally (1994) stated that in foreseeable future mankind will continue the prolongation of a number of working hours to attain greater progress. This prediction has largely been achieved, and mankind has successfully extended the day-time conditions by developing more successful ways of lighting the night. Besides sky glow, two other very noticeable negative products of over-bright and poorly directed lights are glare and light trespass or intrusion (figure 3). Glare is causing distraction or even inability to properly see the area that is supposed to be visible. Light trespass or light intrusion is unproductive spilling of light that is causing discomfort and annoyance in highly populated areas. The amount of disturbance caused by light intrusion is increasing under the influence of urbanization and some countries try to reduce it with adopting new laws. For example, in the United Kingdom, light trespass is an offense under the criminal law for more over than 10 years now. A group of environmental issues is very diverse but they all relate to the negative effect on the aesthetic value of naturally dark sky scenery (Mizon, 2002).

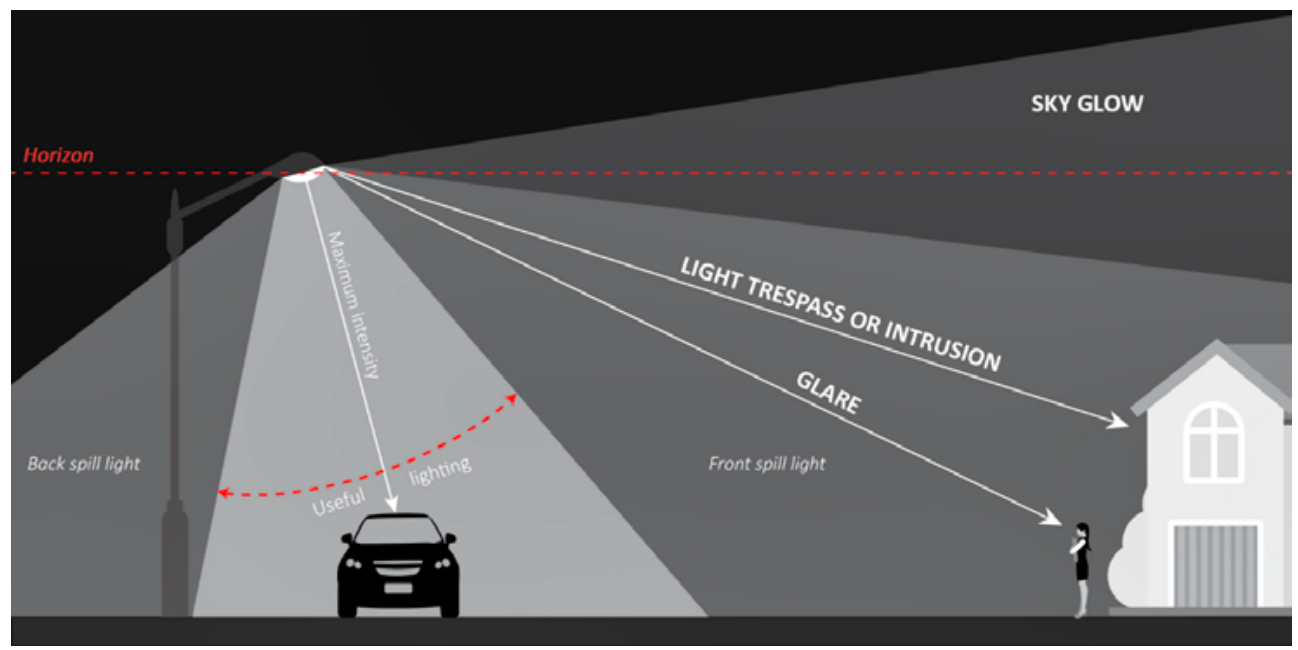

Figure 3. Forms of light pollution

Not only the mankind is losing the spectacle of cosmos that has been continuing inspiration for all kinds of scientific and cultural milestones, but a great disturbance starts to occur in natural cycles of light and dark in ecosystems (Falchi et al., 2011). Early evolution of mammals began in nocturnal phase. Only after the extinction of the dinosaurs, mammals felt safe to come out into the light of the day and start a new stage of evolution in diurnal phase (Menaker et al., 1997; Bowmaker, 2008). Humans are considered to be day-active species but some of the vital functions are processing under natural darkness. Natural day-night cycle controls the molecular circadian clocks which play key role in metabolism and growth. Circadian photoreceptors evolved 500 my ago and they are still present in most organisms, including humans (Dunlap, 1999). Any kind of changes in circadian clock functioning may cause metabolic, sleep and performance irregularities (figure 4). Perhaps the most dangerous disorder is reduced production of 


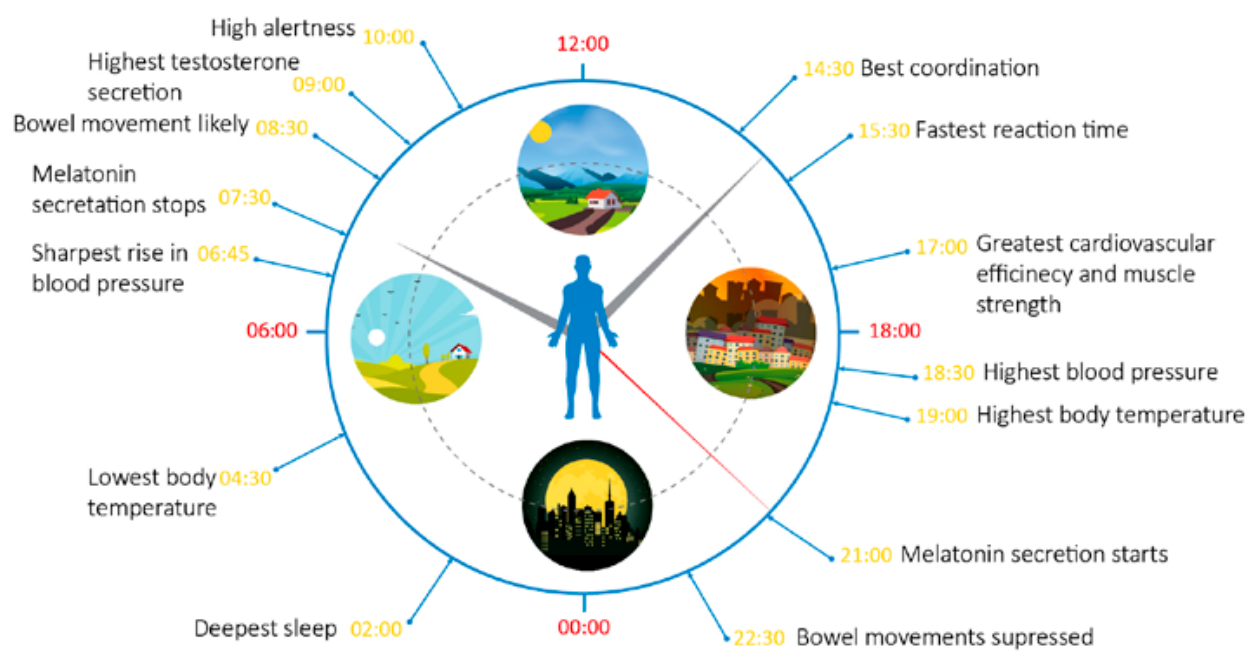

Figure 4. Human circadian rhythm

(Source adapted from Smolensky and Lamberg 2001)

the hormone melatonin. Melatonin is an oncostatic and anti-carcinogenic agent and at reduced amount of this hormone in the blood, the chances of developing some type of cancer increase (Glickman et al., 2002; Anisimov, 2006; Klog et al., 2008; Stevens, 2009).

Unlike humans and animals, plants showed the lowest sensitivity to light pollution. They need light for survival and in some cases, strong illumination stimulates plant growth. However, the excessive amount of light has the greatest impact on sensitive seasonal plants - their growth, flowering, and development. The impact of light pollution on plants has not gain enough of attention so far, cause most of the research on agriculture is related to the positive influence of light on plant growth. Long-term effects on seasonal plants and vegetation in urban areas are yet to be shown in future research (Briggs, 2006; Bennie et al., 2016) Compared with plants, nocturnal animals react to the slightest amount of light in the natural darkness. Their behavior and the way they feed, orient and reproduce is fully adapted to the natural conditions of the night (Longcore and Rich, 2004; Hölker et al., 2010). Due to the excessive diversity of studies conducted on different animal species affected by light pollution (e.g. Johnsen et al., 2006; Fuller, 2007; Kempenaers et al., 2010), only the basic negative effects will be presented. In most studies alteration of artificial light is shown as an indirect factor of stress for nocturnal animals. However, there are direct effects that are mainly associated with airborne and marine fauna. The most common examples are birds that collide with illuminated obstacles and disorientation of sea turtle hatchlings, which causes them to turn towards land. Long-term consequences are associated with irregularities in reproduction and migration of insects, amphibians, birds et cetera, but also with disturbances in the food chain. For example, many insects are attracted to light around which they fly until they die of exhaustion. Reduction of the total number of insects reduces the amount of food for other animals that feed on them. Likewise, daytime feeders can extend their activities under illumination and increase the predatory impact on nocturnal species (Hölker et al., 2010). 
Finally, inappropriate public and private lighting wastes energy and therefore contributes to increased carbon dioxide emissions and global warming. For example, United States is wasting $\$ 6.9$ billion a year for generating electricity for improper public lighting, which is equivalent to 66 million metric tons of $\mathrm{CO}_{2}$. For comparison purposes, the same amount of $\mathrm{CO}_{2}$ would be reduced, if 9.5 million cars from of the road are removed (Gallaway et al., 2010). Therefore, besides developing the technology for ecological sources to power the lighting (such as solar panels over the luminaire), of the same importance is to reduce the production of useless energy scattered above the horizon or to limit the intensity and duration of decorative lighting during the night hours.

\section{POTENTIAL VULNERABILITY OF PROTECTED AREAS IN A.P. VOJVODINA}

The territory of Autonomous Province Vojvodina has always been an important transit area. Therefore, a number of cities developed along the important roads that intersect this region. As previously mentioned, larger urbanized areas are accompanied by the greater amount of light pollution (Mizon, 2002). Figure 6 shows the biggest emission centers of light pollution in the territory of Vojvodina. It is easy to notice that the capital of the province, Novi Sad, is the biggest pollutant of all cities. In addition to being an important transit territory, the A.P. Vojvodina is an area with various natural resourc-

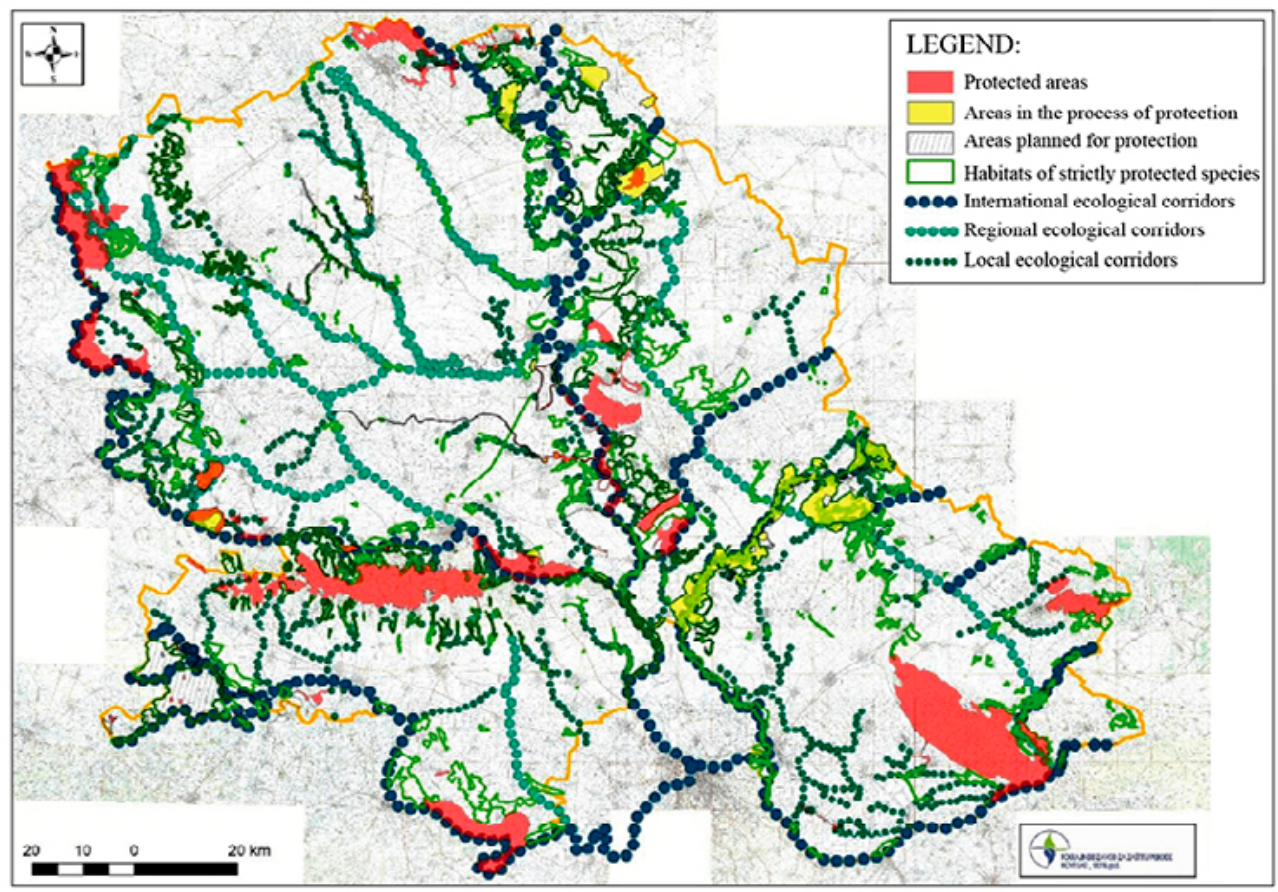

Figure 5. Protected areas and ecological corridors of A.P. Vojvodina

(Source: Institute for nature conservation of Vojvodina Province) 
es such as a national park, special nature reserves, a number of protected nature parks et cetera (Tomić et al., 2004). Since there have not been any individual accurate measurements of light pollution on the territory of Vojvodina, aim of this paper is to indicate potentially endangered natural areas in the vicinity of the largest light pollution emitters. Because of the great diversity of natural resources of Vojvodina, the emphasis will be put on avifauna as an extremely sensitive group toward this type of pollution. According to the data obtained from the www.lightpollutionmap.info, the quality of clear night sky in the urban core of the Novi Sad is very low ranging from $\sim 18$ to $\sim 19 \mathrm{mag}$./ $\mathrm{arc} \mathrm{sec}^{2}$. For comparison purposes, Excellent dark-sky site values range from 21.7-22.0 mag./arc $\mathrm{sec}^{2}$.

The National Park "Fruška Gora" which is an important habitat for plant and animal species, is inimmediate vicinity of Novi Sad (Figure 5). National Park is also marked as an Important Bird Area (IBA) by European experts. Furthermore, the Fruška Gora Mountain is very urbanized. A significant number of smaller settlements developed on mountain slopes. Only four major settlements Šid, Ruma, Sremska Mitrovica and Inđija are marked on the map, but there is the undisputable influence of the Novi Sad and Belgrade as remote emitters of light pollution. Special nature reserve (S.N.R. hereinafter) "Koviljsko-Petrovaradinski rit", which is located in the northeastern area of Fruška Gora, is even under greater influence from the Novi Sad (Figure 6). This reserve is also

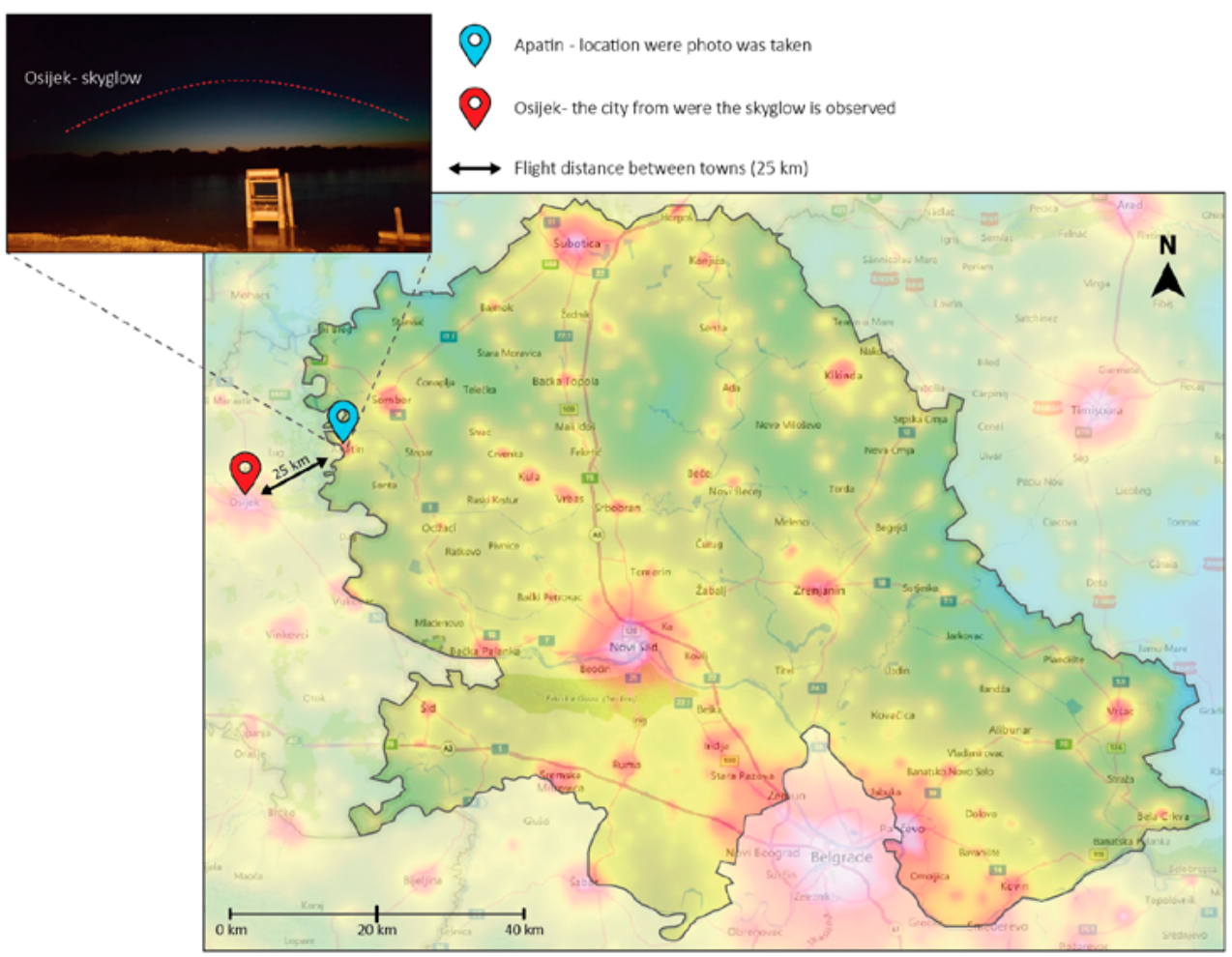

Figure 6. Light pollution map combined with sky glow photograph (Map source: www.lightpollution.info; Photo: Jelena Dunjić) 
very important area for the avifauna (Tomić et al., 2004). Undoubtedly the biggest of light pollution in Serbia is Belgrade, which is located near the southern border of the Vojvodina and S.N.R. Obedska Bara, known throughout Europe for its natural wealth, is in the vicinity of Belgrade. The greatest value of Obedska Bara is avifauna that counts more than 220 species. Important centers of avifauna can also be found in the north of Vojvodina: S.N.R. "Gornje Podunavlje", Protected Nature Park "Palić" et cetera (Figure 5) (Tomić et al., 2004). The greatest amount of light pollution that threatens north of the province comes from two major cities Subotica and Sombor.Besides light pollution sources located inside the borders of Vojvodina, cities from neighboring countries, which are close to the border, must be taken into account. There are several cities located near the border with Croatia while in the north and east only two cities radiate higher values of pollution (Szeged-Hungary and Timisoara-Romania) (Figure 6).

\section{CONCLUSIONS}

Light pollution in Serbia is an almost completely unknown concept. The aim of this study was to present basic information about this form of pollution and draw attention to the situation on the territory of Vojvodina. Some basic assumptions are made about the values of light pollution in the vicinity of protected natural areas and the overall conclusion is worrisome. It is urgent to take measures to reduce light pollution, and also to work on prevention as the growing trend of urbanization in Vojvodina is present. The best way to do achieve this is to educate the society in order to raise awareness about the light pollution, and at the same time to initiate comprehensive research of both - precise measurements and impacts on endangered flora and fauna.

\section{REFERENCES}

Anisimov N.V. (2006). Light pollution, reproductive function and cancer risk. Neuroendocrinology Letters 27, 35-52

Aubrecht, C., Stojan-Dolar, M., De Sherbinin, A., Jaiteh, M., Longcore, T., \&Elvidge, C. D. (2010). Lighting governance for protected areas and beyond - Identifying the urgent need for sustainable management of artificial light at night. Earth, 1-12.

Azam, C., Le Viol, I., Bas, Y., Zissis, G., Vernet, A., Julien, J. F., \& Kerbiriou, C. (2018). Evidence for distance and illuminance thresholds in the effects of artificial lighting on bat activity. Landscape and Urban Planning, 175, 123-135. https://doi.org/10.1016/j. landurbplan.2018.02.011

Bennie J., Davies W.T., Cruse D., Gaston J.K. (2016). Ecological effects of artificial light at night on wild plants. Journal of Ecology 104, 611-620

Bowmaker J.K. (2008). Evolution of vertebrate visual pigments. Vision Res. 48, 2022-2041

Briggs W.R. (2006). Physiology of plant responses to artificial lighting, In: Rich C., Longcore $\mathrm{T}$ (Eds). Ecological consequences of artificial night lighting. Island press, Washington, 389-441 
Cinzano P., Falchi F., Elvidge C.D. (2001). The first World Atlas of the artificial night sky brightness, Monthly Notices of the Royal Astronomical Society 328, 689-707

Crawford, D.L. (1991). IAU Commission 50 Report: Identification and Protection of Observatory Sites, Reports on Astronomy, IAU Trans. XXIA, 593-598

Dunlap J.C. (1999). Molecular bases for circadian clocks, Cell 96, 271-290

Elsahragty M., Kim J. L. (2015). Assessment and strategies to reduce light pollution using Geographic Information Systems, Procedia Engineering 118, 479-488

Falchi F., Cinzano P., Elvidge D.C., Keith M.D., Haim A. (2011). Limiting the impact of light pollution on human health, environment and stellar visibility. Journal of Environmental Management 92, 2714-2722

Fuller R.A., Warren P.H., Gaston K.J. (2007). Daytime noise predicts nocturnal singing in urban robins. Biology Letters 3, 368-370

Gallaway T., Olsen N.R., Mitchell M.D. (2010). The economics of global light pollution. Ecological Economics 69, 658-665

Gaston, K. J., Duffy, J. P., Gaston, S., Bennie, J., \& Davies, T. W. (2014). Human alteration of natural light cycles: Causes and ecological consequences. Oecologia, 176, 917-931. http://dx.doi.org/10.1007/s00442-014-3088-2.

Glickman G., Levin R., Brainard C.G. (2002). Ocular Input for Human Melatonin Regulation: Relevance to Breast Cancer. Neuroendocrinology Letters 23,17-22

Hollan, J. (2009). What is light pollution, and how do we quantify it? Workshop Paper at Darksky 2007 Conference, 1-12. Retrieved from http://amper.ped.muni.cz/light/lp_ what_is.pdf

Hölker F., Wolter C., Perkin K.E., Tockner K. (2010). Light pollution as a biodiversity threat. Trends in Ecology and Evolution 25, 681-682

Johnsen S., Kelber A., Warrant E., Sweeney A.M., Widder E.A., Lee R.L., HernandezAndres J. (2006). Crepuscular and nocturnal illumination and its effects on color perception by the nocturnal hawkmoth Deilephilaelpenor. Journal of Experimental Biology 209, 789-800

Kempenaers B., Borgström P., Loës P., Schlicht E., Valcu M. (2010). Artificial Night Lighting Affects Dawn Song, Extra-Pair Siring Success, and Lay Date in Songbirds. Current Biology 20, 1735-1739

Kloog I., Haim A., Stevens G.R., Barchana M., Portnov A.B. (2008). Light at night codistributes with incident breast but not lung cancer in the female population of Israel. Chronobiology International 25, 65-81

Kyba M.C.C., Garz S., Kuechly H., de Miguel A.S., Zamorano J., Fischer J., Hölker F. (2015). High-Resolution Imagery of Earth at night: New Sources, Opportunities and Challenges. Remote Sensing 7, 1- 23

Longcore T., Rich C. (2004). Ecological light pollution, Frontiers in Ecology and the Environment, 191-198

Lyytimäki J., Tapio P., Assmuth T. (2012). Unawareness in environmental protection: The case of light pollution from traffic, Land Use Policy 29, 598-604

Lyytimäki J. (2013). Nature's nocturnal services: Light pollution as a non-recognized challenge for ecosystem services research and management, Ecosystem Services 3, 4448 
Lyytimäki J. (2015). Avoiding overly bright future: The systems intelligence perspective on the management of light pollution, Environmental Development 16, 4-14

McNally D. (1994). The Effect of Civilization on Observational Astronomy, in The Vanishing Universe, Proceedings of the IAU/ICSU/UNESCO meeting Adverse environmental impacts on astronomy: An exposition. Paris, p. 3

Menaker M., Moreira L.F., Tosini G. (1997). Evolution of circadian organization in vertebrates. Brazilian Journal of Medical and Biological Research 30, 305-313

Mikuž H., Zwitter T. (2005). Širjenjeumetnesvetlobe $\mathrm{v}$ atmosferi in vplivnaonesnaženjenočneganeba s primeriizSlovenije, Zbornik: Svetloba in okolje, Ljubljana, 55-66

Mizon, B. (2002). Light Pollution: Responses and Remedies Second Edition, Springer, New York, $10-88$

Mohar A. (2005). Svetlobnoonesnaženje, bleščanje in primerjalnemeritve, Zbornik: Svetloba in okolje, Ljubljana, 67-84

Report of the council on science and public health. (2016). Human and Environmental Effects of Light Emitting Diode (LED) Community Lighting. American Medical Association

Riegel W.K. (1973). Light Pollution: Outdoor lighting is a growing threat to astronomy, Science 179, 1285-91

Smolensky, M., Lamberg, L. (2001). The Body Clock Guide to Better Health: How to Use Your Body's Natural Clock to Fight Illness and Achieve Maximum Health. Macmillan.

Stevens G.R. (2009). Light-at-night, circadian disruption and breast cancer: assessment of existing evidence. International Journal of Epidemiology 38, 963-970

Tomić P., Romelić J., Kicošev S., Besermenji S., Stojanović V., Pavić D., Pivac T., Košić K., (2004). Zaštićenaprirodna dobra iekoturizamVojvodine, Departman za geografiju, turizamihotelijerstvo, Novi Sad, 6-138 